\title{
The effect of foot reflexology on sleep quality among high risk pregnant women: A randomized controlled trial
}

\author{
Masoumeh Nasiri ${ }^{1}$, Fatemeh Ranjkesh ${ }^{1}$, Maryam Mafi ${ }^{1}$, Mojtaba Senmar ${ }^{1}$, Seyedeh Zahra Hosseinigolafshani ${ }^{1 *}$
}

1 Qazvin University of Medical Sciences

\begin{abstract}
During pregnancy, women experience changes in sleep patterns and poor sleep quality is a common complaint as pregnancy progresses. The aim of this study was to investigate the effect of foot reflexology on sleep quality in high risk pregnant women. In this randomized controlled trial, 72 women with high risk pregnancy were recruited and were assigned to reflexology and control group ( $\mathrm{n}=36$ in each group). The intervention group received 30 Minute foot reflexology twice a week, for four weeks. The control group received routine prenatal care. Before and after the intervention, the Sleep Condition Indicator Scale was used to assess sleep quality. After implementation of intervention independent t-test showed significant differences between the intervention and the control group in quality of sleep. The results of paired t-test revealed Significant improvement of sleep quality in the intervention group $(p<0.05)$. In the control group, sleep quality significantly decreased $(p<0.05)$. The results of present study may suggest that foot reflexology as a noninvasive and non-pharmacological nursing intervention can improve sleep quality in high risk pregnant women.

Keywords: Foot Reflexology, Complementary Medicine, Quality of Sleep, High Risk Pregnancy.
\end{abstract}

\section{Introduction}

Pregnancy is a unique and natural physiological process in women's life. However, the presence of underlying or unexpected diseases in the woman or the fetus can complicate pregnancy and lead to unwanted consequences. The complications of pregnancy and childbirth are main causes of mother death (Cunningham, Leveno, Bloom, Spong, et al., 2018). The prevalence of high risk pregnancies in the whole world is reported to be\% 20. Also, \%50

*Correspondence: z.hoseinigolafshani@qums.ac.ir Qazvin University of Medical Sciences, Qazvin, Iran.

Received: 21 August 2018 Accepted: 04 November 2019

Sleep and Hypnosis

Journal homepage:

http://www.sleepandhypnosis.org

ISSN:1302-1192 (Print) 2458-9101 (Online) of perinatal deaths occur in high risk pregnancies (Cunningham, Leveno, Bloom, \& Hauth, 2018; Kheiriat, Aamanialavijeh, Araban, \& Kheiriat, 2014; Mortazavi, Damghanian, Motaghi, \& Shariati, 2012) This group of women should be identified before childbirth or even before pregnancy using specific criteria. A high-risk pregnancy is one of greater risk to the mother or her fetus than an uncomplicated pregnancy. They are women with a history of chronic diseases such as diabetes, cardiovascular disease, hypertension, gestational diabetes, bleeding, amniotic fluid loss, pain and preterm delivery, lack of proper weight gain, age above 35 years or under 18 years (Cunningham, Leveno, Bloom, Spong, et al., 2018).

Sleep is one of the humans' physiological needs, whose desirable quality is essential for maintaining the individual's health and treatment of the disease (Elliott, Mckinley, \& Cistulli, 2011). Sleep distur- 
bances can result in fatigue, major depression, daytime sleepiness, impaired functions, increased cardiovascular complications, decreased quality of life and increased mortality and morbidity (Malekzadegan, Moradkhani, Ashayeri, \& Haghani, 2010; Nayeri, Ghanei, \& Rezaee, 2012; Rezaei, Moghadam, \& saraylu, 2013). Pregnancy can affect women's sleep pattern and ability in dealing with their daily activities due to systemic changes resulted from hormonal, mental, emotional and physical changes (Cunningham, Leveno, Bloom, \& Hauth, 2018). Sleep disturbances are a recognized problem in pregnancy, to the extent that the American Sleep Disorders Association has proposed the existence of "pregnancy-associated sleep disorder" (Yan, 2017). Different studies have reported that the prevalence of sleep disorders in the third trimester of pregnancy was \%75 (Gay, Richoux, Beebe, \& Lee, 2017; Gelaye et al., 2017; Wang et al., 2017). Indeed, poor sleep quality is one of the most common complaints in pregnancy (Tsai, Lin, Kuo, Sleep, \& Thomas, 2012).

Treatment of poor sleep quality remains challenging as some of the more commonly used sleep inducing medications such as benzodiazepines and hypnotic benzodiazepine receptor agonists may be associated with adverse neonatal outcomes (Reichner, 2015).

Therefore, it seems that non_ invaisive and non_pharmacological management methods are preferable to these kinds of treatments (Mirzaie, Mohammad-Alizadeh-Charandabi, Goljarian, Mirghafourvand, \& Hoseinie, 2018). One of the non-pharmacological and non-mechanical methods is reflexology, a branch of alternative and complementary medicine (Weller, 2014). Reflexology is based on the belief that feet, hands and ears are minor maps of the entire body organs and applying appropriate pressure on the points which are specific for each organ creates a balance in different systems of the body and reduces tension and stress (Tiran, 1996). One theory about foot reflexology massage is that psychological stress is responsible for $\% 75$ of problems and health complications in humans. More than 7000 nerves exist in each foot; when manipulated by foot massage, these are stimulated to reduce the stress and relax the body, resulting in body equilibrium (Rahmani, Naseri, Salaree, \& Nehrir, 2016).

The study by Li et al. (2011) on the effect of foot reflexology on postpartum sleep disturbances showed improvements in sleep quality (Li, Chen, Li, Gau, \& Huang, 2011). Some studies identified the relationship between reflexology and low back pain (Cherniack et al., 2008). decreased fatigue in pregnant women (Pourghaznein \& Ghafari, 2007) improvement in sleep quality after lunch (Akbarzadeh, Toosi, Zare, \& Sharif, 2013; Cherniack et al., 2008; Pourghaznein \& Ghafari, 2007; WHo, 2014). improvement in sleep quality in menopausal women (Asltoghiri \& Ghodsi, 2012).

However, in search of the databases, we found no study examining effect of reflexology on sleep quality among high risk pregnant women. Therefore, we aimed to assess whether foot reflexology could affect quality of sleep in this group.

\section{Material and methods}

\section{Study design}

This was a randomized controlled trial to investigate the effect of foot reflexology on sleep quality in high risk pregnant women from Mar to Jun 2018. Women with gestational diabetes and high blood pressure were considered as a high risk pregnancy. The setting of the study was the prenatal care clinic affiliated with Qazvin University of Medical Sciences.

Sample size: The sample size was calculated using the following statistical formula. "With regard to $\alpha=0.05$ and $\beta=0 / 1$, sample size was estimated. With attrition rate $\% 20$, finally 36 pregnant women were included in each group.

$\mathbf{N}=\left(\mathbf{Z}_{1-\sigma / 2}+\mathbf{Z}_{1-\beta}\right)^{2}\left(\sigma_{1}{ }^{2}+\sigma_{2}{ }^{2}\right) / \mathbf{d}^{2}$

$n=(1.96+1.28)^{2}\left((2.1)^{2}+(1.7)^{2}\right) /(1.62)^{2}$

$=\mathbf{2 9}$

\section{Inclusion/exclusion criteria}

Inclusion criteria were willing to participate in the study, aged between 18_35 years, Gestational age 28-32 weeks (Close, Sinclair, Mc Cullough, Liddle, \& Hughes, 2016), ability to understand verbal Persian. 
Exclusion criteria were participants with neurological diseases, disease on foot skin, open lesion/ wound, scar tissue. Edema, toe deformities, current use of complementary treatment, and Have a history of psychological or anxiety disorders based on medical records or the self-report.

\section{Participants and procedure}

In total, 274 pregnant women were assessed for eligibility. In this group, 49 women were excluded because of not meeting inclusion criteria and 20 women refused to participate. Finally 205 high risk pregnant women remained. From this group 72 pregnant women selected due to simple random sampling method and were randomly allocated to two the intervention and control group $(n=36$ in each group). Participants in the intervention group received foot reflexology twice a week (each session 30 minute) for four weeks. Foot reflexology was based on the principle that reflex points on the feet correspond to every organ, gland and part of the body. For example, the toes represented the head and ball of the foot represented the chest and lung region. The intervention was carried out in a private room at the pre-natal clinic with the provision of privacy of the women. Before the intervention, education about what reflexology was and what might be expected during the intervention was provided to the women. All women completed the Sleep Condition Indicator Scale before the study to assess their baseline quality of sleep. The women were placed in a comfortable supine position and received a total of 30 minute foot reflexology over a period of four consecutive weeks. It is recommended that each session of reflexology was performed within 10-45 min (cevik, 2013; tabar \& Basaran, 2008). Olive oil was applied as a lubricant for the massage. Sampling from the groups was performed in different times to prevent contaminations between the women. Reflexology was administered to all women by one researcher who received theoretical and practical training on reflexology and had a formal certificate. This intervention method was developed by Eunice Ingham (Byers, 1997; Ingham, 1997), and was supported by the INTERNATIONAL INSTITUE OF REFELEXOLOGY. The control group only received the routine prenatal care.

\section{Data collection instruments}

The following tools were used for data collection:

1. The demographic characteristics such as age, education level, employment, previous pregnancy and previous delivery were collected by the researcher through personal interviews. The validity of this tool was approved by nursing and midwifery faculty members.

\section{Sleep Condition Indicator (SCI)}

The SCI was informed by the development phase for the DSM- 5 insomnia disorder, coupled with published research diagnostic criteria and recommended quantitative parameters for sleep disturbance (American-Psychiatric-Association, 2010; Reynolds \& Redline, 2010). The eight_items SCI generated comprised two quantitative items on sleep continuity (item 1, getting to sleep; item 2, remaining asleep), two qualitative items on sleep satisfaction/ dissatisfaction (item 4, sleep quality; item 7, troubled or not), two quantitative items on severity (item 3 , nights per week; item 8 , duration of problem) and two qualitative items on attributed daytime consequences of poor sleep (item 5, effects on mood, energy or relationships (personal functioning); item 6, effects on concentration, productivity or ability to stay awake (daytime performance). Each item was scored on a 5-point scale (0_4). The possible total score ranges from o to 32 , with higher values indicative of better sleep (Espie et al., 2014). It had a robust internal consistency ( $\alpha \geq 0.86)$ and showed an appropriate convergent validity with the Pittsburgh Sleep Quality Index and Insomnia Severity Index (Espie et al., 2014).

Since this tool was used in Iran for the first time, the research team initially translated the tool based on the WHO protocol (who, 2007). Next, its psychometric properties were assessed in a group of 310 pregnant women referred to Kosar Health Center affiliated with Qazvin University of Medical Sciences. Exploratory and confirmatory factor analysis including quantity and quality of sleep and the consequence of low sleep quality were extracted. Two-factor fitting of the scale was confirmed using standard indices. Convergent and divergent validity, internal consistency and stability of the tool were reported (Hosseinigolafshani \& nasiri, 2018). 


\section{Data analysis}

Data was analyzed using the SPSS (version 24). The Kolmogrov-Smirnov test was performed to assess the normality of data. The women's demographic data was displayed using frequency, mean and standard deviation. Chi-Square test was used to assess differences in categorical data between the groups. Independent and paired t-test were conducted to assess the effects of reflexology on quality of sleep. P value less than 0.05 was considered statistically significant.

\section{Ethical consideration}

This study was approved by the ethics committee affiliated with Qazvin University of Medical Science (decree cod: IR.QUMS.REC.1396.305). Participants were informed about study aims and procedures before signing an informed consent document. Moreover, the research protocol was registered in the Iranian Register of clinical trials (IRCT20180514039650N1).

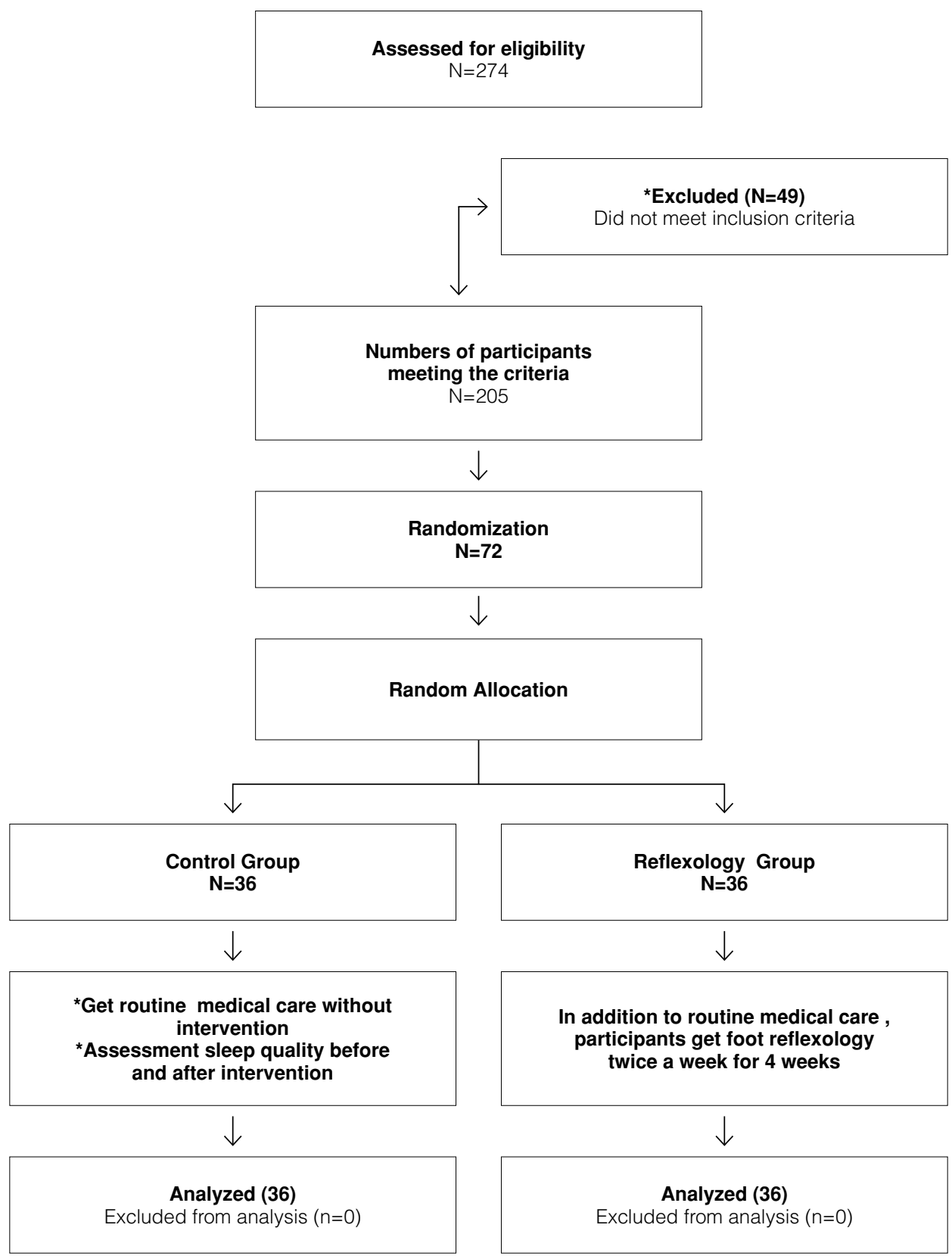

Figure 1. CONSORT flow diagram 


\section{Results}

\subsection{Socio-demographic characteristics of the women}

The personal and social characteristics of the women in the groups were presented in Table 1. The study was conducted with the participation of 72 pregnant women. The mean age was $28.8 \pm 5.6$ years. In terms of education, 35 (\% 48.6) had Diploma, they were housewives 70 (\%97.2). There was no significant differences between the two groups in terms of the underlying variables such as age, education level, occupation and number of pregnancy and the previous delivery (Table 1 ).

Table 1. Baseline characteristics of the women in the groups

\begin{tabular}{|c|c|c|c|c|}
\hline Variables & $\begin{array}{c}\text { Total sample } N(\%) \\
(72)\end{array}$ & $\begin{array}{c}\text { Intervention group } N(\%) \\
(36)\end{array}$ & $\begin{array}{c}\text { Control group } N(\%) \\
(36)\end{array}$ & $\begin{array}{c}P \\
\text { value }\end{array}$ \\
\hline Age $(\mu \pm S D)$ & $27.5 \pm 6.2$ & $29.5 \pm 9.8$ & $28.5 \pm 8.6$ & ${ }^{\circ} 0.9$ \\
\hline Educational status & & & & b 0.5 \\
\hline Illiterate & $6(8.3)$ & $2(2.7)$ & $4(5.6)$ & \\
\hline High school & $19(26.4)$ & $9(12.5)$ & $10(13.9)$ & \\
\hline Diploma & $35(48.6)$ & $17(23.6)$ & $18(25)$ & \\
\hline Collegiate & $12(16.7)$ & $8(11.2)$ & $4(5.5)$ & \\
\hline \multicolumn{5}{|l|}{ Occupation } \\
\hline Employed & $2(2.8)$ & $2(2.8)$ & $0(0)$ & \\
\hline Housewife & $70(97.2)$ & $34(47.2)$ & $36(50)$ & b 0.15 \\
\hline \multicolumn{5}{|l|}{ Previous pregnancy } \\
\hline $0-2$ & $54(75)$ & $29(40)$ & $25(35)$ & \\
\hline $3-4$ & $18(25)$ & $7(9.7)$ & $11(15.3)$ & a 0.2 \\
\hline \multicolumn{5}{|l|}{ Previous delivery } \\
\hline $0-2$ & $56(90.2)$ & $33(45.9)$ & $32(44.1)$ & a 0.9 \\
\hline $3-4$ & $7(9.7)$ & $3(4.3)$ & $4(3.4)$ & \\
\hline
\end{tabular}

$\mathrm{a}=$ Chi-square, $\mathrm{b}=$ Fisher exact, $\mathrm{c}=$ Independent $\mathrm{t}$-test

\subsection{Effect of foot reflexology}

The Sleep Condition Indicator Scale was used to assess sleep quality. According to table 2, independent t-test showed significant differences between the intervention and the control group in quality of sleep. The results of paired t-test revealed significant improvement of sleep quality in the intervention group $(\mathrm{p}<0.05)$. In the control group, sleep quality significantly decreased ( $\mathrm{p}<0.05)$.

Table 2. Comparison of mean score of sleep quality in the women before and after the intervention in the groups

\begin{tabular}{|c|c|c|c|}
\hline Quality of sleep & $\begin{array}{c}\text { Before } \\
\text { Mean } \pm S D\end{array}$ & $\begin{array}{c}\text { After } \\
\text { Mean } \pm S D\end{array}$ & $\begin{array}{c}\text { P-value/ } \\
\text { paired-t test }\end{array}$ \\
\hline Intervention & $15.6 \pm 9.8$ & $21.3 \pm 3.6$ & $\begin{array}{l}t=-6.5 \\
p<0.001\end{array}$ \\
\hline Control & $18.6 \pm 1.3$ & $12.5 \pm 5.7$ & $\begin{array}{c}t=7.6 \\
P<0.001\end{array}$ \\
\hline Independent T-test & $\begin{array}{c}t=-1.8 \\
p=0.063\end{array}$ & $\begin{array}{c}t=8.1 \\
p<0.001\end{array}$ & \\
\hline
\end{tabular}




\section{Discussion}

The aim of this study was to investigate the effect of foot reflexology on sleep quality among high risk pregnant women. The results of this study showed that the mean score of sleep quality in the intervention group was increased. Different levels of sleep quality in the reflexology group were improved after the intervention, but in the control group, both the overall sleep quality and different levels of sleep were deteriorated. The results of studies by Mardasi et al in sixty mother who referred to postpartum care. (2013), Asltoghiri et al in women during menopause. (2012), Kheyri et al in women with unwanted pregnancy experience. (2016) and Farrokhian et al in hemodialysis patients. (2016) reported that foot reflexology improved sleep quality or reduced sleep disorders in patients (Asltoghiri \& Ghodsi, 2012; Farrokhian, Solimani, Sheikhi, \& Alipour, 2016; Kheyri, Bastani, \& Haghani, 2016; Mardasi, Tadayon, Najar, \& Haghighizadeh, 2013)

The studies by MalekShahi et al in patients with end-stage renal disease undergoing hemodialysis. (2018), Grady et al in shift workers. (2016). Li et al in postpartum women. (2011) and seyedrasooli et al in Men 65 to 70 years old. (2013) also reported that foot reflexology improved sleep quality and reduced sleep disorders in individuals (Grady \& Helen, 2016; Li et al., 2011; Malekshahi, Aryamanesh, \& Fallahi, 2018; Seyedrasooli et al., 2013). All of the above studies investigated this intervention on the quality of sleep in different groups. On the other hand, other studies were conducted to investigate the effect of foot reflexology on other variables. Shahsavari et al. (2017) studied the effect of foot reflexology massage on anxiety and physiological parameters in patients with Bronchoscopy candidates and showed that this intervention reduced anxiety and improved the physiological parameters of individuals (Shahsavari, Abad, \& Yekaninejad, 2017). Heidari et al. (2017) studied in patients with coronary angiography, and their results showed that reflexology decreased anxiety among these patients (Heidari, Rejeh, Heravi-Karimooi, Tadrisi, \& Vaismoradi, 2017). In a study by Soheili shahreza et al. (2014) with tittle The effects of reflexology on physical symptoms in women with multiple sclerosis re- sults showed reflexology was effective in relieving fatigue and pain severity in patients with multiple sclerosis (Soheili shahreza, nazari, shayegannejad, \& valiani, 2014). In a study by Akin-Korhan et al. (2016) in patients with fibromyalgia, reflexology reduced their pain (Akin-Korhan, Uyar, Eyigör, Yönt, \& Khorshid, 2016). Shermeh et al. (2009) studied on Effect of foot reflexology on sternotomy pain after CABG surgery, and their results showed that the use of reflexology is effective in reducing sternotomy pain in post-operative patients (Shermeh \& Bozorgzad, 2009). No studies were conducted to explore the effect of foot reflexology in women with high risk pregnancy; therefore studies conducted in other fields were included. Moghimi Hanjani et al. (2015) studied the effect of foot reflexology on pain and anxiety of Primigravida women. They showed that reflexology immediately after the intervention had no effect on pain of individuals, but differences in the groups were significant half, one and two hours after the intervention (Moghimi-Hanjani, Mehdizadeh-Tourzani, \& Shoghi, 2015). This finding was justified by the subjective nature of pain. Accordingly, the results of evaluations over longer periods of time were consistent with the results of this study. The study by Valizadeh et al. (2015) examined the effect of foot washing and reflexology on the quality of sleep in elderlies. It was found that both these interventions improved the quality of sleep in people, but the comparison confirmed that there was no significant difference between the sub-scales of sleep quality and the overall score of the two interventions (Valizadeh, Seyyedrasooli, Zamanazadeh, \& Nasiri, 2015).

It is true that our study's intervention similar to the Valizadeh et al.'s study improved the quality of sleep in individuals, but it is noteworthy that there was difference between foot washing as a low skilled method and reflexology as a high level skill. Also, patients may be more comfortable with foot washing. In a study by Da-silva et al. (2015) on the effect of foot reflexology massage on the improvement of patient's leg in type II diabetes, it had no effect on the foot improvement such as skin and hair (da-Silva, Chaves, de-Carvalho, Carvalho, \& Iunes, 2015). This study showed similar results with our study in 
terms of the improvement of some indices. However, diabetes is a chronic disease and patients need to live with it for a long time. On the other hand, mothers with high risk pregnancy have different conditions and mainly have reversible complications. In terms of differences between the results of various studies with those of our study, the time of reflexology is somehow an effective factor. In this study, the standard and within the prescribed technique (30 minutes (15 minute for each leg) for four weeks was used. Despite many advances in pharmaceutical methods for the treatment of sleep disorders, the use of these methods has always been accompanied by its own consequences and consequently, scientists have always sought non-pharmacological methods for the improvement of patients' sleep quality (Farrokhian et al., 2016). For this reason reflexology massage of the foot causes physiological and local changes in the body and provides a deep state of relaxation in the mind and body. Therefore, most people report an improvement in their health and well-being (Amini et al., 2017). Generally, foot reflexology is useful in improving the quality of sleep of individuals, although no study was found on the impact of this intervention on the quality of sleep and its different levels in women to provide a more accurate analysis, but it can be said that this intervention in patients with acute conditions and those with signs and symptoms is more effective than those patients with chronic diseases and prolonged symptoms and complications. Moreover, one of the most important aspects of this intervention can be safety for baby in pregnant women. Because there are no side effects and just normalization of organ function is performed (Schlegel, Whalen, \& Williamsen, 2016). Therefore, it is imperative that the use of reflexology and its mechanism of action are well understood so that midwives and other HCP can advise, discuss and document pregnant women's usage (McCullough, 2015). In some studies, the research team increased the time and number of post-intervention follow-ups, and reached different and reliable results. Therefore, the difference in results or non-compliance in some studies is justified by the results of our study.

Finally, in the topic of effectiveness of reflexolo- gy, whatever the results of studies showed that this technique is an effective intervention in improving mental health of individuals. The important point is that some studies have compared this technique with drugs and invasive interventions and so maybe a not significant difference in these studies is related to the nature of the comparisons, because if you compare the reflexology massage with the routine medical care, Differences are likely to be Significant. For this reason, we have seen significant results in the more appropriate comparison. A part from this, it should be noted that now the foot reflexology massage is a complementary treatments and complementary is a complete explanation for these differences.

\section{Conclusion}

The results of this study showed that performing foot reflexology improved sleep quality in women with high risk pregnancy. However, in the control group, sleep quality significantly reduced. This finding shows, if we don't have plan to improve sleep quality in pregnant women, naturally as the gestational age increased, sleep quality will decreased. Considering the general tendency of the community towards non-pharmacological and non-invasive interventions such as massage, reflexology is recommended as a non-invasive, non-prescriptive, safe and simple technique for nurses to manage and improve sleep quality in practice. Another important point is that reduction of the quality of sleep associated with an increase in the gestational age necessitates attentions to certain interventions, so that nurses can help with improving the quality of sleep during pregnancy. Therefore, nurses should increase their knowledge and skills in reflexology to improve the quality of sleep and prevent poor sleep quality by participating in short-term workshops and training courses. Complementary therapy research centers and organizations can develop programs to provide training and education to nurses and other clinicians and empower them for using such therapies in their daily practice. The incorporation of reflexology into routine care and along with pharmacologic methods can provide nurses with a holistic approach to better manage patient's sleep quality. 


\section{Limitation and suggestion}

The short follow-up period (just once after the intervention) was a limitation of this study. It is suggested that studies on the effect of reflexology massage on the quality of sleep in women with high risk pregnancies should be conducted with further follow ups, as well as the impact of this technique on other relevant variables require further research.

\section{References}

Akbarzade, M., Toosi, M., Zare, N., \& Sharif, F. (2013). Effect of relaxation and attachment behaviors training on anxiety in first-time mothers in Shiraz city, 2010: A randomized clinical trial. J Qom Univ Med Sci, 6(4),14-23.

Akin Korhan, E., Uyar, M., Eyigör, C., Yönt, G.H., \& Khorshid, L. (2016). Effects of Reflexology on Pain in Patients With Fibromyalgia. Holistic nursing practice, 30(6),351-9.

American Psychiatric Association. (2010). Moo Insomnia Disorder. DSM-5 Development Web site. http://www.dsm5.org/ProposedRevision/Pages/proposedrevision.aspx?rid=65\#/Updated.

Amini, Z., Roshanravan, M., Bahrami, H.R., Sanagoo, A., Jouybari, L., \& Kamali, A. (2017).The effects foot reflexology on the level of depression in patients under hemodialysis. 2 Journal of Nursing Education, 5(6),33-9. doi: 10.21859/jne-05065

Asltoghiri, M., \& Ghodsi, Z. (2012).The effects of Reflexology on sleep disorder in menopausal women. Procedia-Social and Behavioral Sciences, 31,242-6. doi:https://doi.org/10.1016/j.sbspro.2011.12.049

Byers, D. (1997). Better Health With Foot Reflexology: The Original Ingham Method. Saint Petersburg, FL: Ingham Publishing.

cevik, K. (2013). complementary and alternative therapy in nursing: reflexology. Journal of Ege University Nursing Faculty, 29,71-82.

Cherniack, E.P., Ceron-Fuentes, J., Florez, H., Sandals, L., Rodriguez, O., \& Palacios, J.C. (2008). Influence of race and ethnicity on alternative medicine as a self-treatment preference for common medical conditions in a population of multi-ethnic urban elderly. Complementary therapies in clinical practice, 14(2),116-23.

Close, C., Sinclair, M., Mc Cullough, J., Liddle, D., \& Hughes, C. (2016). A pilot randomised controlled trial (RCT) investigating the effectiveness of reflexology for managing pregnancy low back and/or pelvic pain. Complement Ther Clin Pract, 23,117-124.

Cunningham, F., Leveno, K., Bloom, S., \& Hauth, J.R.D. (2018). Williams Obstetrics 23th Edition Mcgraw Hill. 23th Editi. New York, 409-414 P.

Cunningham, F., Leveno, K., Bloom, S., Spong, C.Y.C., Dashe, J., Cunningham, F., \& Leveno, K. B.S. (2018). Disorders Of Amniotic Fluid (Williams Obstetrics.24th Ed, New York, 2014, The Mcgraw-Hill Companies. 24th Ed. New York, 189-215 P.

da Silva, N.C.M., Chaves, É.d.C.L., de Carvalho, E.C., Carvalho, L.C., \& Iunes, D.H. (2015). Foot reflexology in feet impairment of peo-

\section{Conflict of interest}

The authors declare no conflicts of interest with respect to the research, authorship, and or publication of this article.

\section{Acknowledgment}

We would like to thank Qazvin University of Medical Science for financial support of this study. Our gratitude should be extended to all pregnant women who participated in this study. ple with type 2 diabetes mellitus: randomized trial. Revista Latino-Americana de Enfermagem, 23(4),603-10. doi: 10.1590/01041169.0036.2594

Elliott, R., McKinley, S., \& Cistulli, P. (2011). The quality and duration of sleep in the intensive care setting: an integrative review. International Journal of Nursing Studies, 48(3),384-400.

Espie, C.A., Kyle, S.D., Hames, P., Gardani, M., Fleming, L., \& Cape, J. (2014). The Sleep Condition Indicator: a clinical screening tool to evaluate insomnia disorder. BMJ open, 4(3),eoo4183.

Farrokhian, R., Solimani, M.A., Sheikhi, M.R., \& Alipour, M. (2016). Effect of Foot Reflexology Massage on Sleep Quality in Hemodialysis Patients: A Randomized Control Trial. Scientific Journal of Hamadan Nursing \& Midwifery Faculty, 24(4),213-20. doi: $10.21859 / \mathrm{nmj}-24041$

Gay, C.L., Richoux, S.E., Beebe, K.R., \& Lee, K.A. (2017). Sleep disruption and duration in late pregnancy is associated with excess gestational weight gain among overweight and obese women. Birth, 44(2),173-80.

Gelaye, B., Addae, G., Neway, B., Larrabure-Torrealva, G.T., Qiu, C., Stoner, L., Fernandez, M.A, Sanchez, S.E., \& Williams, M.A. (2017). Poor sleep quality, antepartum depression and suicidal ideation among pregnant women. Journal of affective disorders, 209,195-200.

Grady, L.H. (2016). The Effects of Reflexology Treatment on Sleep Quality in Shift Workers: Cardiff Metropolitan University. Dissertation.

Heidari, F., Rejeh, N., Heravi-Karimooi, M., Tadrisi, S.D., \& Vaismoradi, M. (2017). Effect of short-term hand reflexology on anxiety in patients before coronary angiography: A randomized placebo controlled trial. European Journal of Integrative Medicine, 16,1-7.

Hosseinigolafshani, S.Z., \& Nasiri, M. (2018). psychometric properties of SCI in sample of Iranian pregnant women. Iranian journal of epidemiology. (inpress)

Ingham, E. (1997). Stories The Feet Can Tell Thru Reflexology: Stories The Feet Have Told Thru Reflexology. Petersburg, FL: Ingham Publishing.

Kheiriat, M., Aamanialavijeh, F., Araban, M., \& Kheiriat, F. (2014). Reasons deemed for an unwanted pregnancy: a qualitative study (unwanted pregnancy). Health Educ Health Prom, 2(2),153-64.

Kheyri, A., Bastani, F., \& Haghani, H. (2016). Effects of Reflexology on Sleep Quality of Elderly Women Undergoing Abdominal Sur- 
gery. JCCNC, 2 (1),11-18.

Li, C.Y., Chen, S.C., Li, C.Y., Gau, M.L., \& Huang, C.M. (2011). Randomised controlled trial of the effectiveness of using foot reflexology to improve quality of sleep amongst Taiwanese postpartum women. Midwifery, 27(2),181-6. doi: 10.1016/j. midw.2009.04.005

Malekshahi, F., Aryamanesh, F., \& Fallahi, S. (2018). The effects of massage therapy on sleep quality of patients with end-stage renal disease undergoing hemodialysis. Sleep and Hypnosis, 20,91-5.

Malekzadegan, A., Moradkhani, M., Ashayeri, H., \& Haghani, H. (2010). Effect of relaxation on insomnia during third trimester among pregnant women. Iran Journal of Nursing, 23(64),52-8.

Mardasi, F., Tadayon, M., Najar, S.H., \& Haghighizadeh, M.H. (2013). The Effect of Foot Massage on Sleep Disorders among Mothers in Postpartum Period. The Iranian Journal of obstetrics, genecology and Infertility, 16(73),19-28.

McCullough, J.E.M. (2015). Reflexology use during Pregnancy. J Yoga Phys Ther, 5,189. doi:10.4172/2157-7595.1000189

Mirzaie, P., Mohammad-Alizadeh-Charandabi, S., Goljarian, S., Mirghafourvand, M., \& Hoseinie, M. B. (2018). The effect of foot reflexology massage on breast milk volume of mothers with premature infants: A randomized controlled trial. European Journal of Integrative Medicine, 17, 72-78.

Moghimi-Hanjani, S., Mehdizadeh-Tourzani, Z., \& Shoghi, M. (2015). The Effect of Foot Reflexology on Anxiety, Pain, and Outcomes of the Labor in Primigravida Women. Acta medica Iranica, 53(8),507-11.

Mortazavi, F., Damghanian, M., Motaghi, Z., \& Shariati, M. (2012). Women's Experiences Of Unwanted Pregnancy. Behbood, 15(6),492-503.

Nayeri, D., Ghaneii, R., \& Rezaee, K. (2012). The Relationship between Restless-Leg Syndrome and Sleep Quality Disorder in Pregnant Women. The Iranian Journal of Obstetrics, Gynecology and Infertility, 15(15),1-7.

Pourghaznein, T., \& Ghafari, F. (2007). The effect of sole reflexology on severity of fatigue in pregnant women. Hayat, 12(4),5-11.

Rahmani, A., Naseri, M., Salaree, M. M., \& Nehrir, B. (2016). Comparing the Effect of Foot Reflexology Massage, Foot Bath and Their Combination on Quality of Sleep in Patients with Acute Coronary Syndrome. Journal of caring sciences, 5(4), 299.

Reichner, C.A. (2015). Insomnia and sleep deficiency in pregnancy. Obstetric medicine, 8(4), 168-171.

Reynolds, C.F, \& Redline, S. (2010). The DSM-V sleep-wake disorders nosology: an update and an invitation to the sleep community. J Clin Sleep Med, 15,9-10.

Rezaei, E., Moghadam, Z.B., \& Saraylu, K. (2013). Quality of life in pregnant women with sleep disorder. Journal of family \& reproductive health, $7(2), 87$.
Schlegel, M.L., Whalen, J.L., \& Williamsen, P. M. (2016). Integrative therapies for women with a high risk pregnancy during antepartum hospitalization. MCN: The American Journal of Maternal/ Child Nursing, 41(6),356-362.

Seyedrasooli, A., Valizadeh, L., Nasiri, k.H., Zamanzadeh, V., Goljariyan, S., \& Gasemi, O. (2013). The effect of reflexology on sleep quality of elderly: A single-blind clinical trial. Medical-Surgical Nursing Journal, 2(1), 18-11.

Shahsavari, H., Abad, M.E.E,. \& Yekaninejad, M.S. (2017). The effects of foot reflexology on anxiety and physiological parameters among candidates for bronchoscopy: A randomized controlled trial. European Journal of Integrative Medicine, 12,177-81.

Shermeh, M.S., \& Bozorgzad, P. (2009). Effect of foot reflexology on sternotomy pain after CABG surgery. Nursing Journal of Intensive Car, 2(2),51-54.

Soheili shahreza, M., Nazari, f., Shayegannejad, V., \& Valiani, M. (2014). The effects of reflexology on physical symptoms in women with multiple sclerosis. complementary Medicine Journal, 4(2),820-830.

tabar, H., \& Basaran, E.B.Z. (2008). introduction to reflexology ,izmir:birlesik matbaacilik, 1st.

Tiran, D. (1996). The use of complementary therapies in midwifery practice: a focus on reflexology. Complementary therapies in nursing \& midwifery, 2(2), 32-37.

Tsai, S.Y., Lin, J.W., Kuo, L.T., \& Thomas, K.A. (2012). Daily sleep and fatigue characteristics in nulliparous women during the third trimester of pregnancy. Sleep, 1,35(2),257-62.

Valizadeh, L., Seyyedrasooli, A., Zamanazadeh, V., \& Nasiri, K. (2015). Comparing the Effects of Reflexology and Footbath on Sleep Quality in the Elderly: A Controlled Clinical Trial. Iranian Red Crescent Medical Journal, 17(11),e20111.. doi: 10.5812/ircmj.20111

Wang, H., Leng, J., Li, W., Wang, L., Zhang, C., Li, W., Liu, H., Zhang, S., Chan, J., Hu, G., \& Yu, Z. (2017). Sleep duration and quality, and risk of gestational diabetes mellitus in pregnant Chinese women. Diabetic Medicine, 34(1),44-50.

Weller, B. (2014). Baillière's Nurses' Dictionary: For Nurses and Health Care Workers (26 ed.): Elsevier.

Organization WH. (2014). Http://Www.Who.Int/Mediacentre/Factsheets/Fs348/En.Url> Http//Www Who Int/Mediacentre/Factsheets/Fs241.

Organization WH. (2007). Process Of Translation And Adaptation Of Instruments. Available from: http://www.who.int/substance_ abuse/research_tools/translation/en/

Yan, Z. (2017). A Study on Factors Affecting Sleep during Pregnancy in Clinical Trials. Arts \& Sciences Electronic Theses and Dissertations. 1167. https://openscholarship.wustl.edu/art_sci_ etds $/ 1167$ 